\title{
PICASSIETTE EVI (LA MAISON PICASSIETTE)
}

\author{
Yrd. Doç. Lale Demir ORANSAY ${ }^{1}$
}

\begin{abstract}
ÖZET
Mozaik antik çağdan günümüze kadar ulaşan ve kaplama yöntemi olarak kullanılan bir dekoratif resim sanatıdır. Çeşitli atıklardan yararlanılarak yapılan mozaik tekniğinin Picasiette tekniği olarak adlandırılmasına ilham kaynağı olan Fransa'nın Chartres kentinde bulunan Picassiette evini tasarlayan Raymond Isidore, sanat eğitimi almadan tamamıla naif duygularla evini mozaikle kaplamıştır. Isidore, renklerini ve yansımalarını beğenerek topladığı cam ve seramik kırıklarını, evinin süslemesinde kullanmıştır. Evinin bütününü mozaikle kaplaması nedeniyle komşuları tarafından deli olarak görülen Isidore'a "Tabak hırsızı, çalıntı tabak" anlamına gelen Picassiette lakabı takılmıştır. Günümüzde, müze olarak gezilebilen bu ev; giriş, evin iç bölümü, şapel, siyah avlu, yazlık ev, bahçeye geçiş, heykelli ve Kudüs duvarının bulunduğu bahçeler, ruhun mezarı ve meyve bahçesi olmak üzere dokuz bölümden oluşmaktadır.

Picassiette evi incelendiğinde, Chartres kenti ve Katedrali'nin hemen hemen evin bütün bölümlerinde konu alındığı görülmüştür. Ayrıca naif yaklaşımlarla yapılmış çiçek, hayvan ve insan figürleri de sıkça göze çarpmaktadır. Isidore'un kimi yerlerde düz renklerden desenler oluşturduğu, kimi yerler de ise desenli seramik kırıklarını bir araya getirerek yeni motifler ortaya çıkardığı izlenmiştir. Evin iç, dış duvarları ve mobilyaları işlevlerini yitirmeden seramik ve cam kırıklarıyla kaplanmışlardır. $\mathrm{Bu}$ makalede yazar, rengarenk görüntüsü ve konularıyla insanda gizemli ve ruhani bir yer izlenimini oluşturan Picassiette evini genel olarak ele alarak evin bölümlerini hem teknik hem de desenler açısından incelemiştir.
\end{abstract}

Anahtar Kelimeler: Picassiette, La maison Picassiette, Mozaik.

\footnotetext{
${ }^{1}$ Anadolu Üniversitesi Engelliler Entegre Yüksekokulu, Seramik Bölümü, Eskişehir; ldemir@anadolu.edu.tr
} 


\title{
THE HOUSE OF PICASSIETTE (LA MAISON PICASSIETTE)
}

\begin{abstract}
Mosaic is a decorative plastic art which is used as a covering method and get through ancient times to today. The mosaic technique which is made by using various waste materials is called Picassiette technique. Raymond Isidore who designed picassiette house in the Chartes town in France and inspired the name of the technique has had no art education and had covered his house with mosaics completely in naive senses. Isidore used the glass and ceramic pieces which he collected previously because he enjoyed their colors and reflections to embellish his house. His neighbors thought him to be insane because he covered all over his house with mosaics and he was nicknamed as picassiette which means "stolen plate or plate stealer". Today the house which can be visited as a museum consists of nine parts as entrance, interior house, chapel, black courtyard, summer house, atrium of the garden, gardens with sculptures and wall of Jerusalem, spirit's tomb and orchard.

When examining the picassiette house, it is seen that the Chartres city and Cathedral have been major theme throughout the house. Human, animal and floral figures made with a naive approach are seen frequently. Isidore seems to make figures from solid colored pieces and also use patterned ceramics to make new designs. The outer and interior walls of the house and the furniture are covered with mosaic without losing their functionality. In this paper the writer revises the Picassiette house which gives a mystic and spiritual appearance with colorful outlook and themes in general and examines the parts of the house both technically and in terms of designs.
\end{abstract}

Keywords: Picassiette, La maison Picassiette, Mosaic. 


\section{Giriş}

“Tabak hırsızı, çalıntı tabak" anlamına gelen Picassiette, Fransa'da Paris’in seksen kilometre güneybatısında yer alan Chartres kentinin St. Cheron bölgesinde Raymond Isidore tarafından inşaa edilmiştir. Picassiette evi (La Maison Picassiette) mozaikleriyle dikkat çekicidir. Picassiette, Raymond Isidore'u deli gibi gören ve küçümseyen komşuları tarafından ona takılan addır.

Isidore, Picassiette evinin inşaatına 1930 yılında başlamış, ancak o yıllarda evini süslemeyi düşünmemiştir. 1935 yılında çevre düzenleyicisi, 1949 yılından emekliliğine kadar da Saint Cheron mezarlığında temizlik işçisi olarak çalışan Isidore 1938 yılında önce iç mekanlar olmak üzere evini süslemeye başlamıştır. Naif duygularla raslantısal olarak tasarıma başlayan Isidore kendini şöyle ifade etmiştir.

İlk önce evimi barınmak için inşaa ettim. Evimi bitirdikten sonra kırlarda gezerken tesadüfen küçük cam parçaları, seramik ve tabak parçaları gördüm. Bunları belli bir amaç olmadan topluyordum. Sadece renkleri ve parlaklıkları ilgimi çekiyordu. Sonra iyilerini seçtim, kötülerini attım. Onları bahçemin bir köşesinde istifledim. O sırada evimi süslemek için bir mozaik yapma fikri aklıma geldi. Başlangıçta duvarlarla sınırlı bir dekorasyon düşünüyordum. (Kloss, 1979: 22)

Önce evinin tavanını, yerleri ve mobilyalarını mozaikle kaplamış, daha sonra evinin dış cephesini ve avluları kaplamıştır. Arkasından ana yapıya bir şapel ve yazlık ev ilave etmiştir. Ayrıca evine bitişik olan arsayı da satın alan Isidore burada bir bahçe oluşturmuş ve mozaikle kaplı heykeller yerleştirmiştir. Son olarak Mavi mezar odasını inşaa etmiş ve evinin süslemesini 1962 yılında bitirmiştir. Henüz hayattayken evinin ünü duyulmuş ve Picassiette evi Isidore tarafından ziyarete açılmıştır. 1981 yılında belediye tarafından satın alınıp 1983 yılında müzeye dönüştürülen ev, tarihi yapı olarak kayıt altına alınmıştır.

\section{Picassiette Evinin Bölümleri}

Isidore oluşturduğu mozaik tasarımlarında genellikle yaşadığı kent olan Chartres'dan betimlemeleri konu almıştır. Chartres katedralinin tasviri evin birçok bölümünde kullanılmış, özellikle de gül pencere motifi, birçok yerde işlenmiştir. Katedralin mozaik gibi görünen vitraylardan oluşan pencereleri büyük ihtimalle Isidore'un evini mozaikle kaplama isteğine ilham kaynağı olmuştur. Evin birçok bölümü mozaikle kaplı olmasına rağmen bazı duvarlarda freskler vardır. Betimlemelerde kullanılan bazı figüratif tasvirler gerçek kişilikleri 
yansıtmamaktadır. Isidore bu tasvirleri kendi düşünceleri doğrultusunda tasarlamıştır. Ona göre bu figürler, yüzler belli kişilere ait değil sadece birer maskedirler. (Kloss, 1979: 24)

Picassiette; giriş, evin iç bölümü, şapel, siyah avlu, yazlık ev, bahçeye geçiş, heykelli ve Kudüs duvarının bulunduğu bahçe, ruhun mezarı ve meyve bahçesi olmak üzere dokuz bölümden oluşmaktadır. (Resim 1)

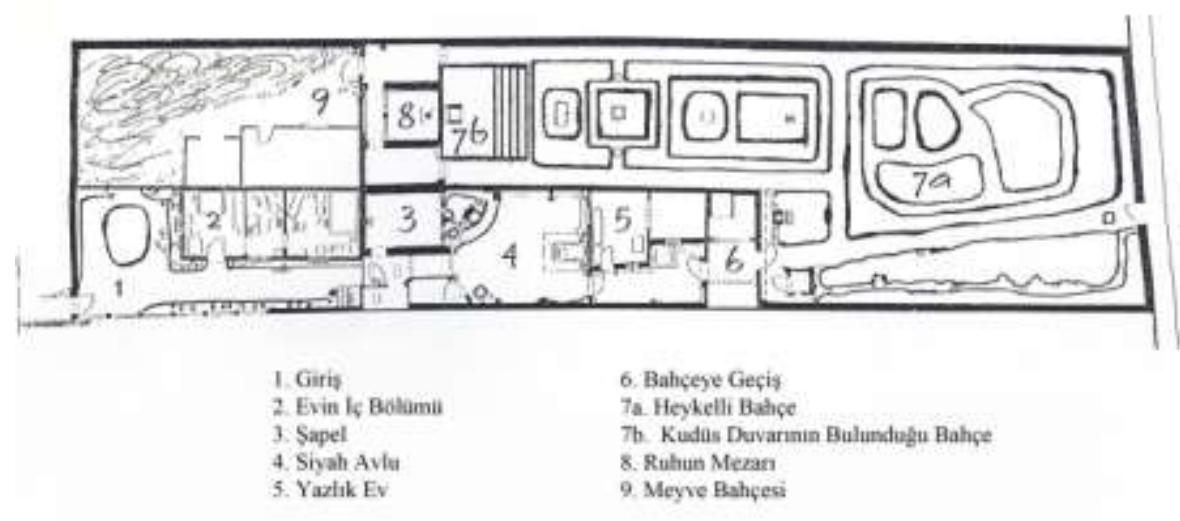

Resim 1 : Picassiette Evinin Planı (Valles-Bled 2007: 2)

\section{Evin Giriş Avlusu ve Dış Cephesi}

Ortasında oval bir çiçeklik bulunan giriş avlusunun duvarlarında, Chartres'da bulunan önemli anıtlar betimlenmiştir. 1944 yılında Alman ordusunun taarruzuyla yıkılan Guillaume Kapısı bu betimlemelerden birisidir. Duvarın diğer panosunda ise Chartres Katedrali betimlenmiştir. Etrafinda yıldıza benzer çiçek motifleri bulunmaktadır. Avludaki yerler de seramik parçaları ile süslenmiştir. Yerde, gül pencere motifleri görülmektedir. Yer kaplamalarında, genellikle beyaz ağırlıktayken üzerindeki desenler de ise renkli seramik kırıkları kullanılmıştır. Evin ön cephe duvarında ise mavi çimento kullanılmıştır. Bu nedenle duvarda mavi etki hakimdir. Evin ön cephesinde, biri altta büyük biri de üstte küçük olmak üzere iki pencere bulunmaktadır. Büyük pencerenin üstünde gül pencere motifi, yanlarında ise saksıda çiçek motifleri vardır. Pencerenin altında Japon evinden esinlenmiş bir betimleme bulunmaktadır. (Resim 2) 


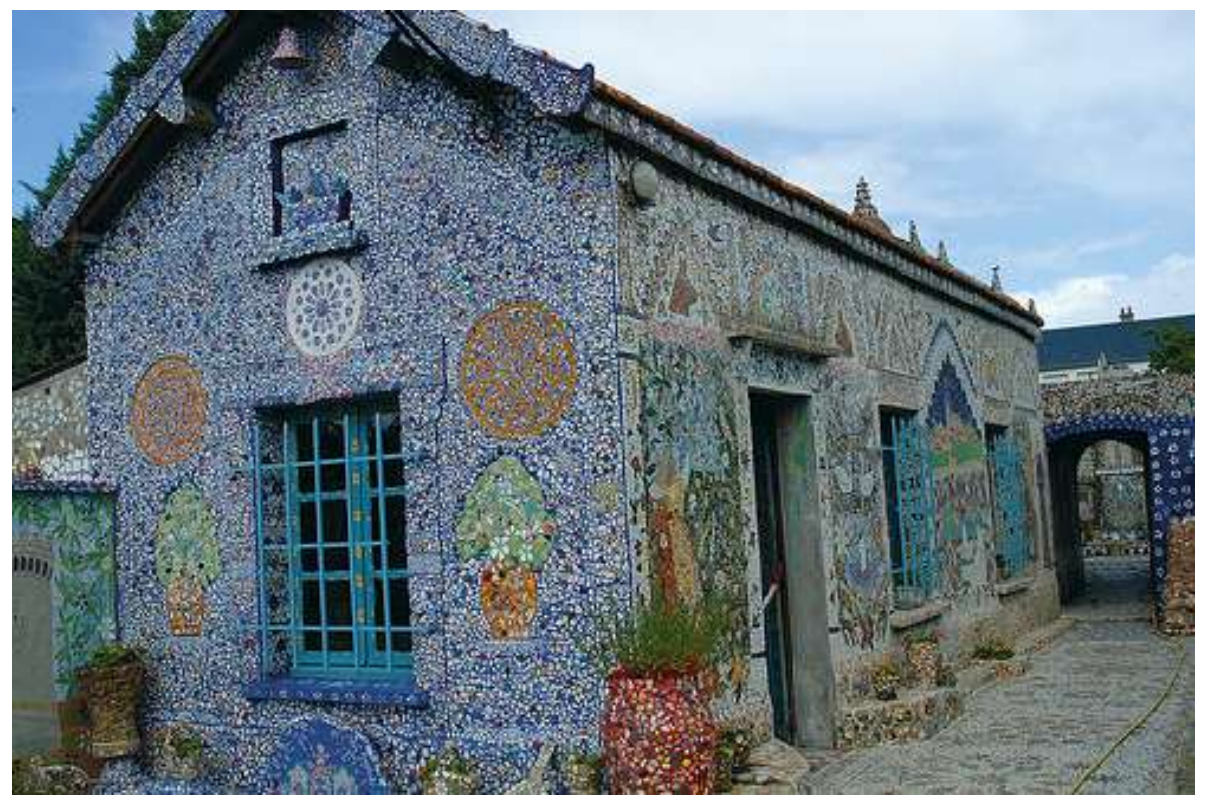

\section{Resim 2 : Picassiette Evi Ön Cephe}

\section{(http://www.thedailytelecraft.com/2012/07/field-trip-maison-picassiette.html)}

Evin yan duvarında iki kadın betimlemesi görülmektedir. Bunlardan sol panodaki bir Filistin kadınını, sağdaki panodaki ise bir Fransız kadınını betimlemektedir. Bu kadınlar birbirlerine doğru bakmaktadırlar. Isidore bu panolar için ; "Fransız oldugum için batılı kadın betimlemesi Fransızdır. Doğulu kadın ise belki Filistinlidir. Birbirini seven iki kızkardeş gibi." (Kloss, 1979: 24) demiştir. Ortadaki panelde ise Chartres kentinin betimlemesi vardır. Ayrıca kelebek ve kuş motifleri de bu duvarı süslemektedir (Resim 2). Avluda seramik kırıklarıyla kaplı saksılar ve dekorasyon amacıyla yerleştirilmiş objeler bulunmaktadır. Binanın saçakları da mozaikle kaplanmıştır (Resim 3). Çatının üzerinde ise Chartres katedralinin betimlemesi görülmektedir. 


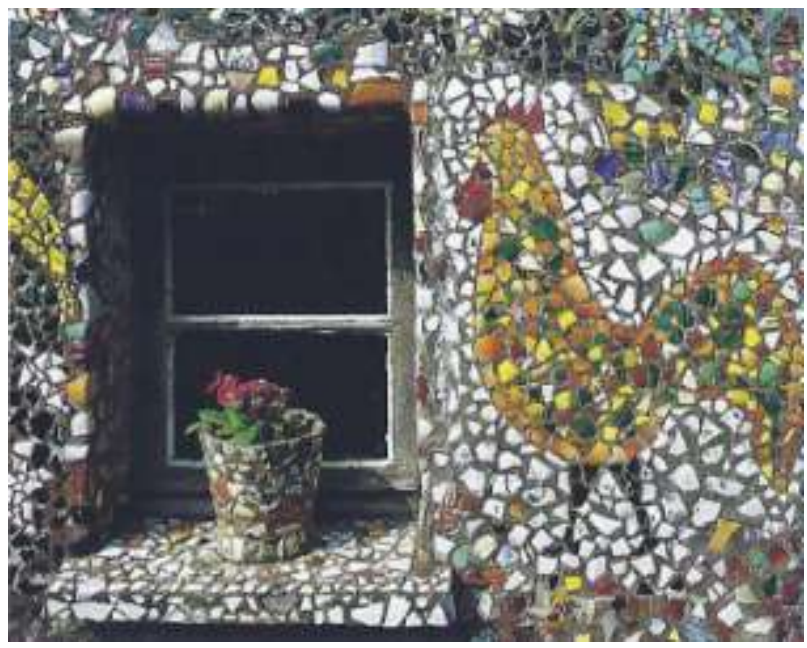

Resim 2: Horoz Figürü

(Valles-Bled 2007: 4)

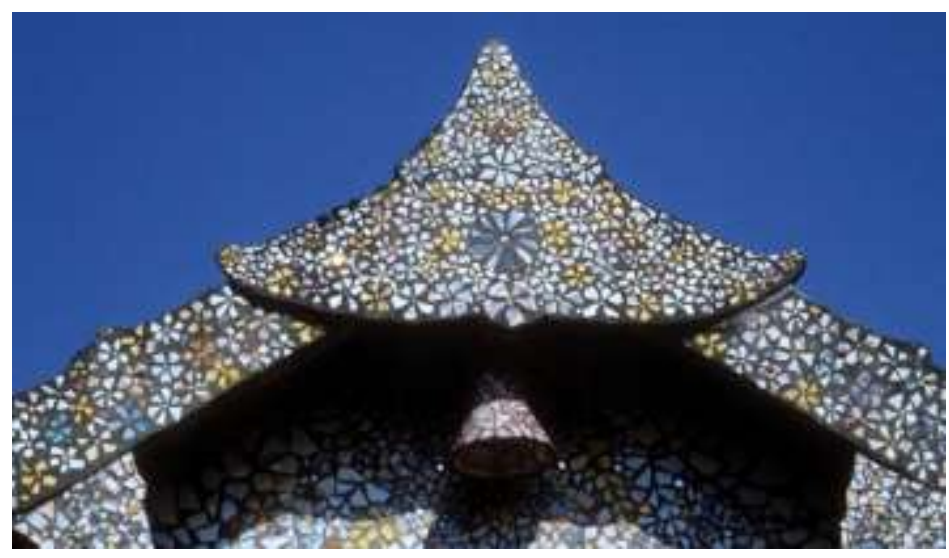

Resim 3: Çatı Saçakları

(http://www.raingod.com/angus/Gallery/Photos/Europe/France/Centre/images/PicassietteEaves01.j pg) 


\section{Evin İç Bölümü}

Evin içi; mutfak, küçük salon (kış salonu) ve yatak odası olmak üzere üç bölümden oluşmaktadır.

Mutfak, aynı zamanda yemek ve oturma odası olarak da kullanılmıştır. Mutfakta, girişin karşısındaki ana duvarda Fransa'nın güneydoğusunda bir manastır kompleksi olan Mont Saint Michel betimlemesi vardır. Fresk olarak yapılan bu betimlemenin etrafında bitkisel motifler bulunmaktadır. Ocak ve bacası, masa, sandalyeler, dolap ve taban tamamen mozaikle kaplıdır. Ancak bu kaplamalar objelerin işlevlerini engellememektedir (Resim 4). Tavanda ise büyük bir çiçek resmi bulunmaktadır.

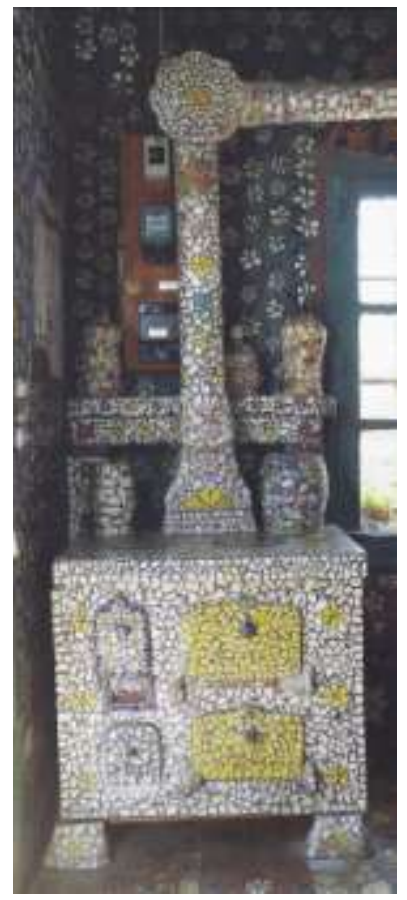

Resim 4 : Mozaik Kaplı Ocak ve Fırın

(Valles-Bled 2007: 7) 
Küçük Salon veya kış bahçesi olarak adlandırılan oda, evin en dar odasıdır. Taban ve mobilyalar mozaikle kaplıdır. Duvarlarda ise freskler bulunmaktadır. Girişin karşısındaki duvarda, çaydan su içen ceylanları gösteren natüralist bir betimleme varken sağ duvarda ise Chartres kenti ve kentin içinden geçen Eure nehri betimlenmiştir. Odada bitkisel motifler yoğun olarak işlenmiştir (Resim 5).

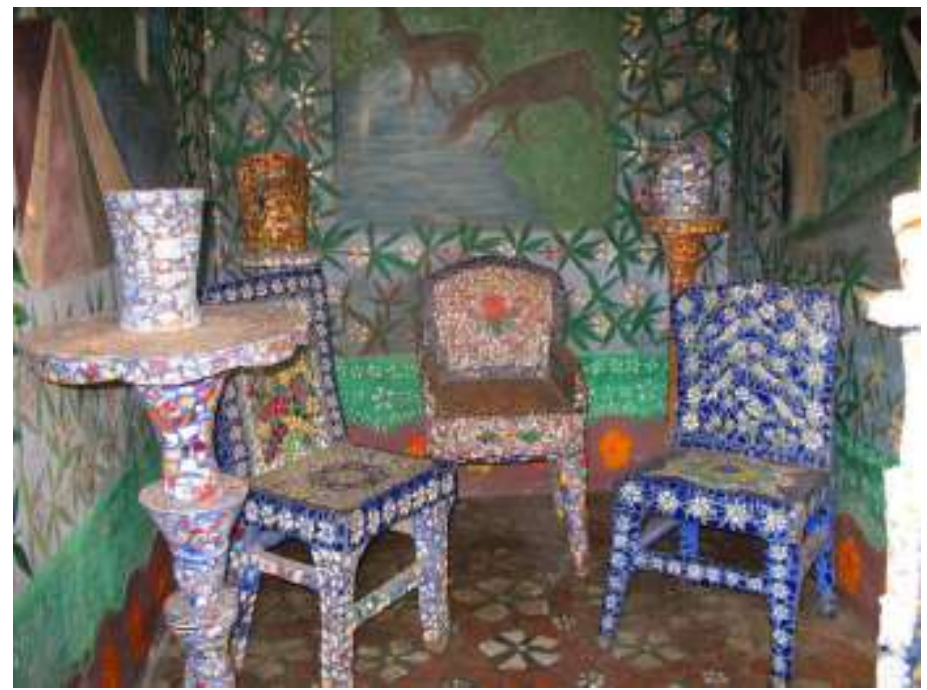

Resim 5: Küçük Salon

(http://www.thedailytelecraft.com/2012/07/field-trip-maison-picassiette.html)

Yatak odasında girişin karşısındaki duvarda doğuyu simgeleyen bir betimleme vardır. Bu betimleme de çöl, vahalar, develer, beyaz giyinmiş bedevileri simgeleyen figürler bulunmaktadır. Yan duvarda ise Paris'te bir köprü olan PontNeuf (Yeni Köprü)'ün hayali bir betimlemesi bulunmaktadır. Yatak, dikiş makinası, komodin, şömine, dolap ve yerler yine mozaikle kaplanmıştır (Resim 6). 


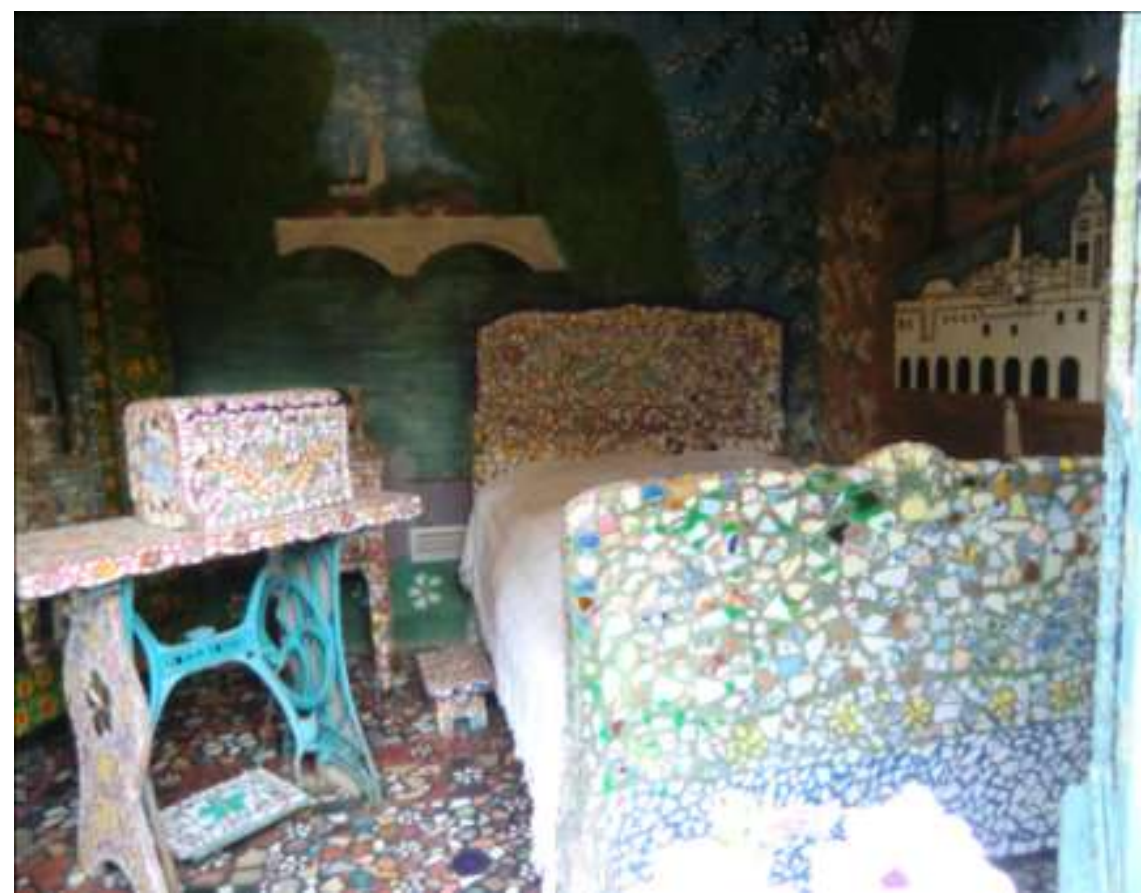

Resim 6 : Yatak Odası

(http://ailonuage.canalblog.com/tag/Musées)

\section{Şapel}

Şapel, evin arkasında doğu duvarına bitişik durumdadır. Her yanı cam ve seramik kırıklarından oluşan mozaiklerle kaplı olan Şapelin ana temaları, İsa'nın doğuşu, çocukluğu ve Meryem'dir. Şapelde baskın renk Chartres Katedralinin vitraylarındaki gibi kobalt mavisidir. Doğu duvarında, altında bir kadeh betimlemesi bulunan büyük bir haçın çevresinde Kudüs'ü simgeleyen tasvirler yer almaktadır. Şapelin batı duvarında ise Chartres kenti ve altında mezarlık simgeleri bulunmaktadır. Bu simgelerin solunda tavukları besleyen bir köylü kadın figürü, sağında ise köpeğiyle sürüsünü bekleyen bir çoban figürü vardır. Bu figürlerin ortasında geride ise sabanla çift süren bir figür bulunmaktadır (Resim 7). Şapelin nişlerinde Meryem ve çocuk tasvirleri yer almaktadır. 


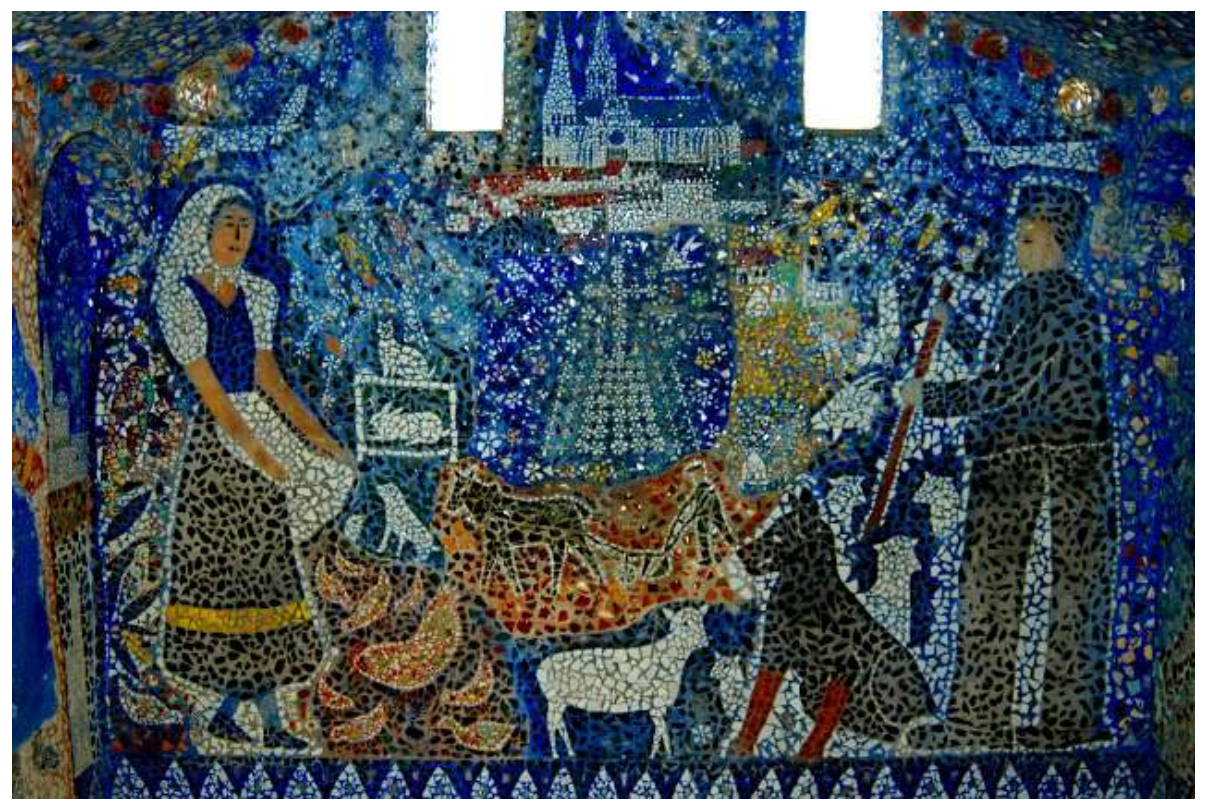

Resim 7: Chartres Kenti Betimlemesi

(http://matinlumineux.blogspot.com/2011/06/maison-picassiette-chartres.html)

\section{Siyah Avlu}

Siyah avlu, evin en dikkat çekici alanıdır. Burada baskın renk Isidore için yerselliği, dünyevi hayatı simgeleyen siyahtır. Siyah renk için, koyu yeşil ve siyah cam kırıkları, beyaz ve diğer renkler için ise kırık seramik parçaları kullanılmıştır.

Avlu girişinin karşısında bir mezar bulunmaktadır. Siyah mezar olarak adlandırılan ve tamamen mozaikle kaplı lahitin üstünde Chartres katedralinin çimentodan yapılmış heykeli bulunmaktadır. Lahitin ön cephesinde Meryem'in tasviri ve altında da gül pencere motifi görülmektedir. Yan cephelerde ise çeşitli kilise betimlemeleri vardır.

Mezarın arkasında bulunan duvar, Chartres duvarı olarak adlandırılmaktadır. Bu duvarın üzerinde mezarın arkasında kalan kısımda büyük bir haç vardır. Duvarda açılan nişlerde farklı kiliselerin tasvirleri bulunmaktadır. Duvarın en üstünde 
Chartres katedrali ve altında da kırmızı çatılı Chartres evlerinin betimlemeleri görülmektedir (Resim 8, 9). Avlunun yan duvarlarında günlük yaşamdan kesitler bulunmaktadır. Bu panolarda hayvan ve insan figürleri ve bitkisel motifler yer almaktadır. Güneye bakan soldaki duvarın merkezinde, şapelde de görülen bir kadın, çoban ve köpeğinin tasviri vardır. Köpek figürü Isidore için sadakati temsil etmektedir. (Valles-Bled 2007: 17)

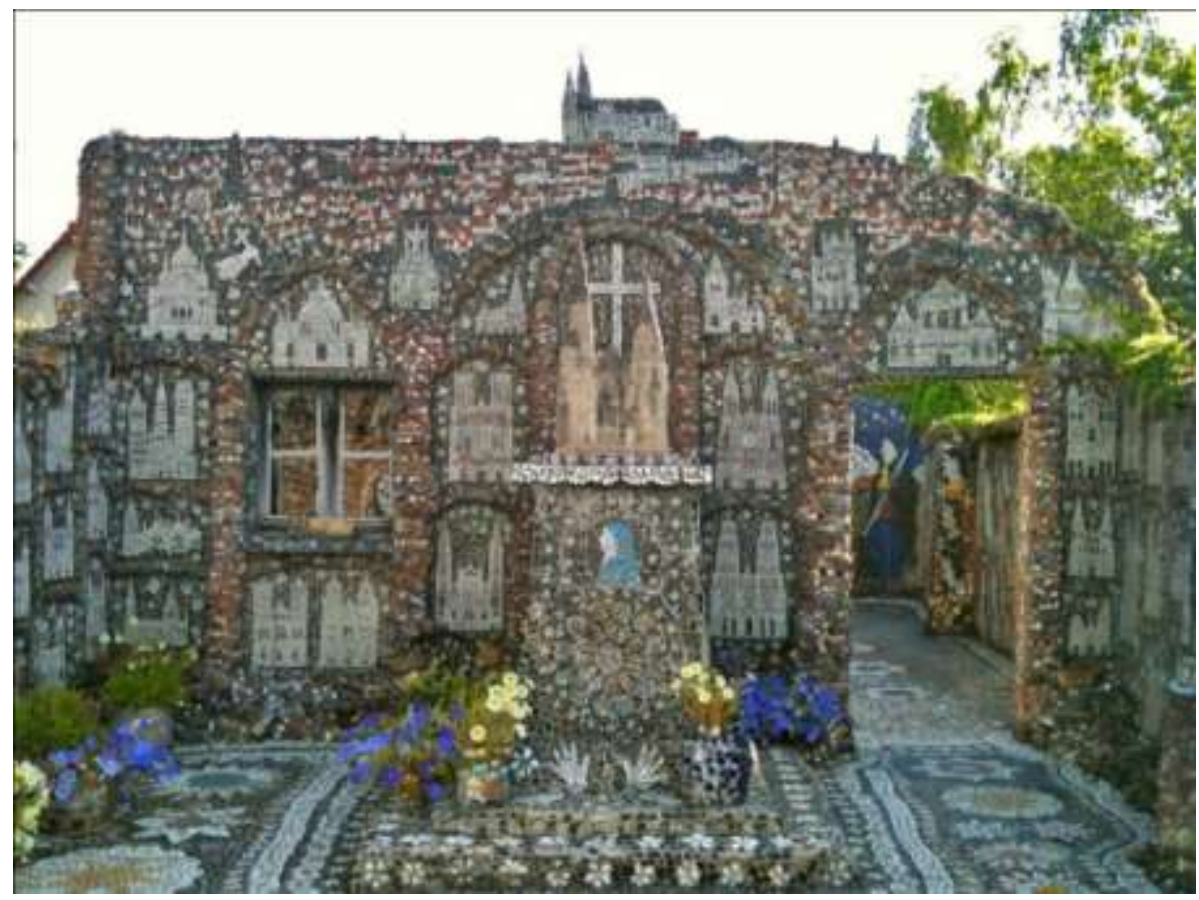

\section{Resim 8: Siyah Avlu}

(http://ailonuage.canalblog.com/tag/Musées) 


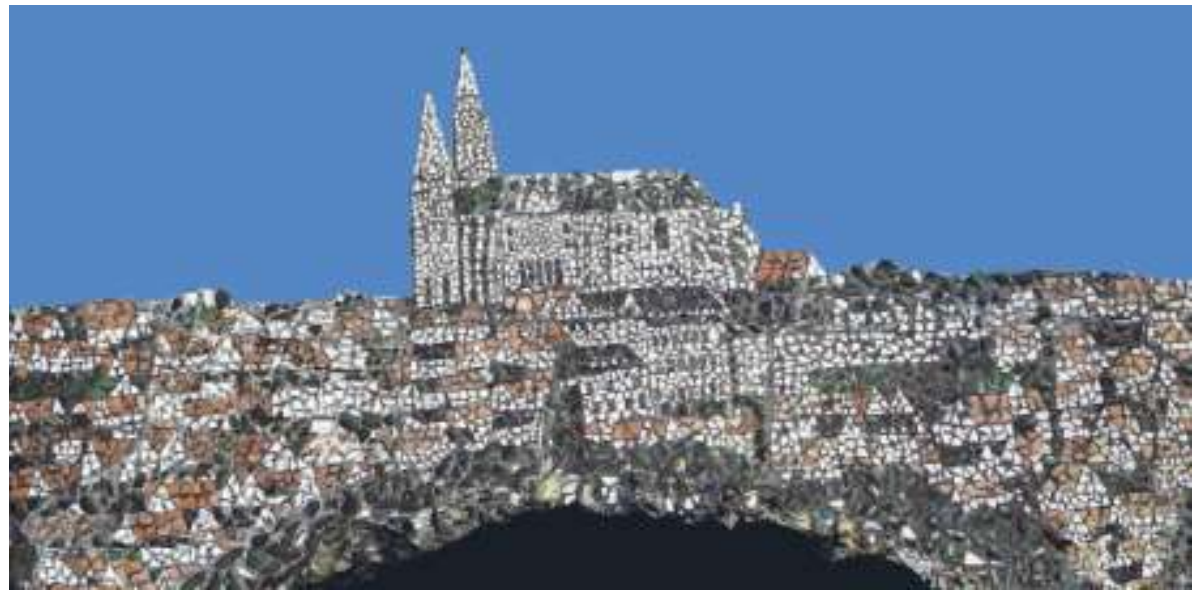

Resim 9 : Chartres Kenti Betimlemesi, Siyah Avlu

(Valles-Bled 2007: 1)

Avlunun solunda mezarın karşısında siyah bir koltuk vardır. Kara Taht denilen bu koltuk Isidore'un koltuğudur. Koltuğun bulunduğu alan basamaklarla yükseltilmiştir. Taht ve çevresi tamamen mozaikle kaplıdır. Tahtın iki yanında saksılar bulunmaktadır. Tahtın solunda bir geyik figürü ve çimentodan şekillendirilmiş, el ele tutuşmuş bir çift görülmektedir. Tahtın sağ tarafındaki alanda ise küçük bir kuyu bulunmaktadır (Resim 10). 


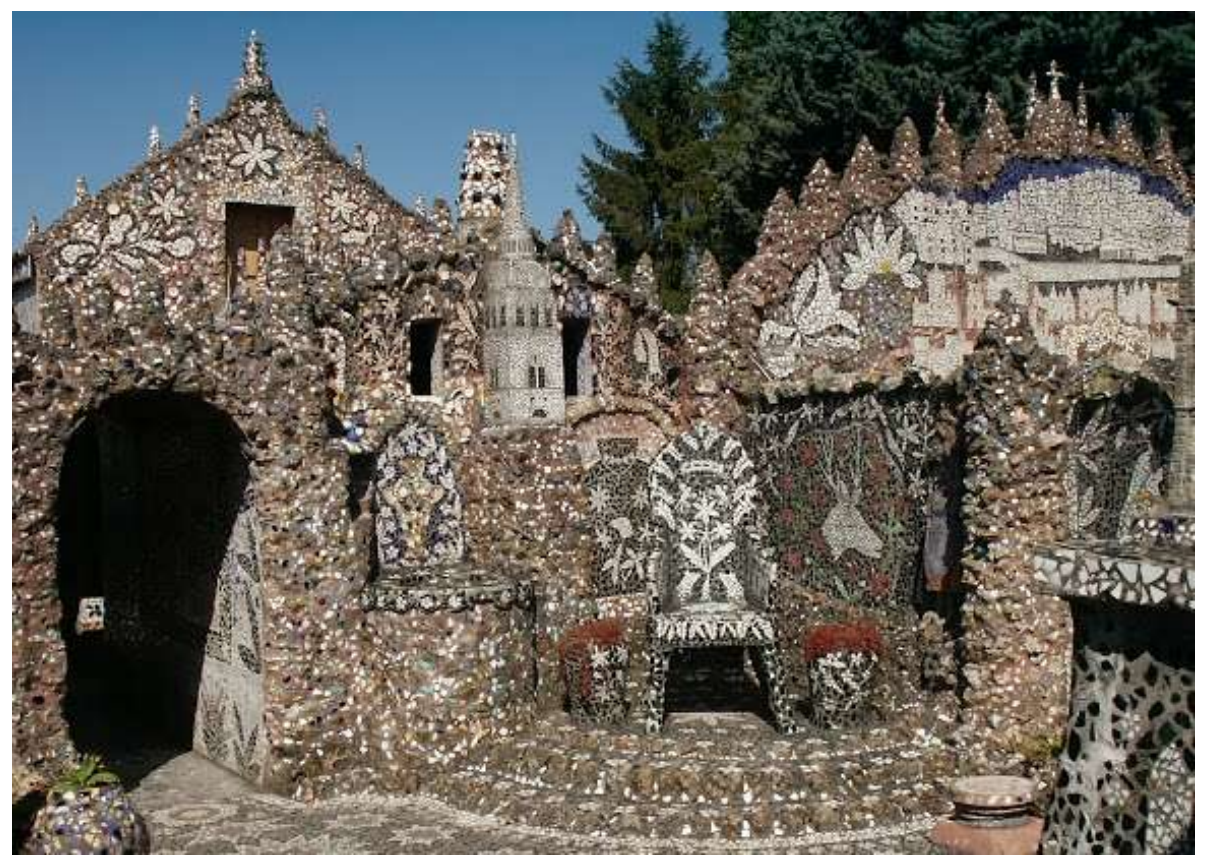

Resim 10 : Siyah Taht, Siyah Avlu

(http://matinlumineux.blogspot.com/2011/06/maison-picassiette-chartres.html)

\section{Yazlık Ev}

Yazlık eve, küçük bir avludan girilmektedir. $\mathrm{Bu}$ evin diş cephesinde Meryem'e müjde sahnesi ve şimşek betimlemeleri bulunmaktadır. Pencerenin sağ tarafındaki köşeye Isidore birçok farklı objeyi aplik etmiştir. Biblolar, çaydanlık emzikleri, kulp ve tabak ayakları gibi malzemeler evin sadece bu duvarında görülür (Resim 11, 12). Evin içi ise dişı kadar özenli süslenmemiştir. Sanki aceleyle yapılmış resim izlenimi veren duvarlarda işçilik, dışı kadar iyi değildir. 


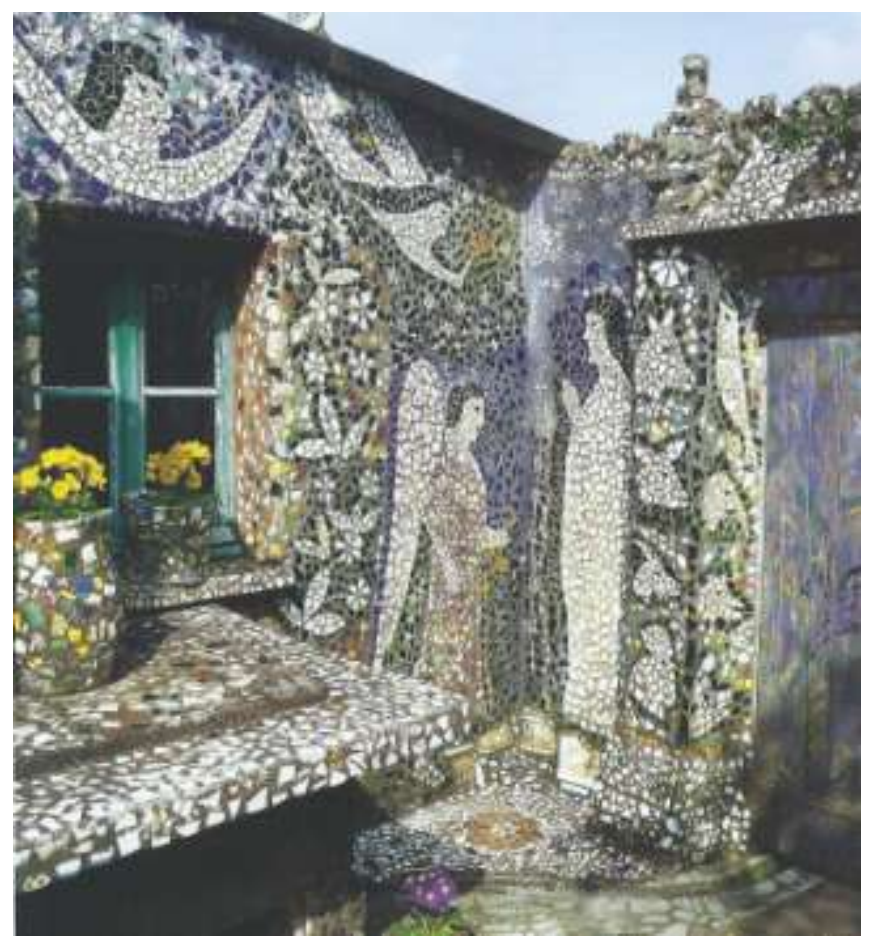

Resim 11 : Meryem'e Müjde Sahnesi

(Valles-Bled 2007: 25) 


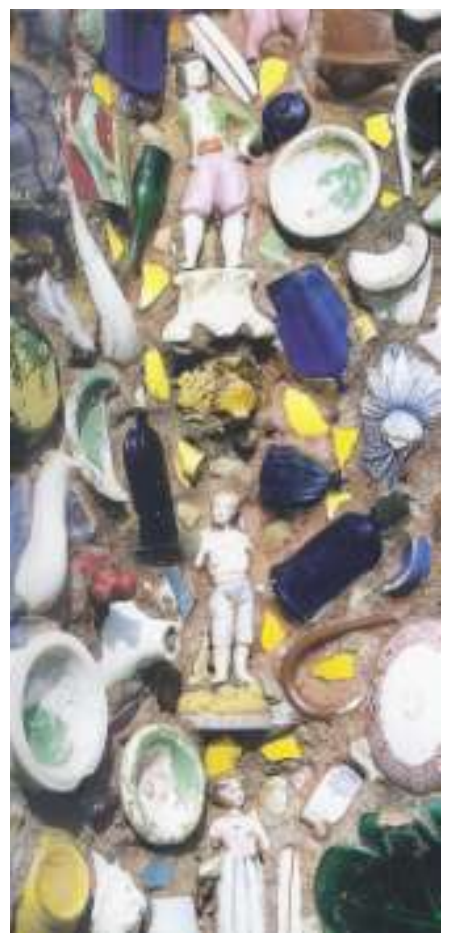

Resim 12 : Yazlık Ev Detay

(Valles-Bled 2007: 35)

\section{Bahçeye Geçiş}

Bahçeye geçişdeki duvarlarda mozaikten çok, figürler, bitkisel tasvirlerden oluşan fresk resimler görülmektedir. Bu betimlerin arasında Monalisa, dönemin ünlü kabere sanatçısı olan Landru, bahçede oturan iki bayan ve bir erkekten oluşan tasvirler bulunmaktadır (Resim 13). 


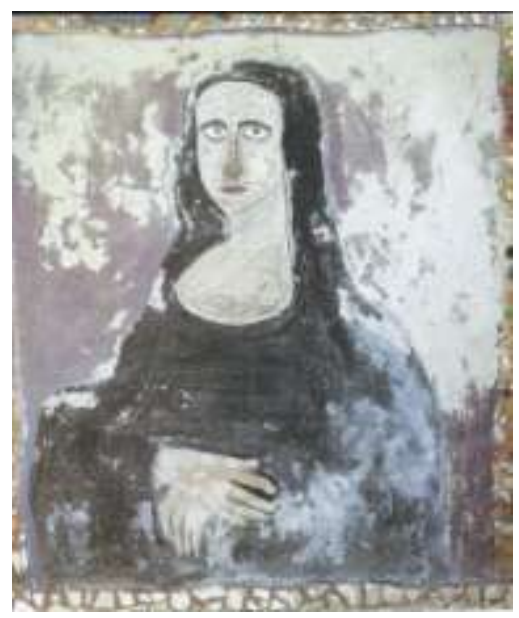

Resim 13: Mona Lisa Betimlemesi

(Valles-Bled 2007: 28)

\section{Bahçe}

Bahçe, Heykelli bahçe ve Kudüs duvarının bulunduğu bahçe olmak üzere ikiye ayrilmaktadır.

Heykelli bahçede bahçeyi dolaşan bir yol bulunmaktadır. Yolun çevresi çiçeklerle kaplıdır. Bu bahçede, Eiffel Kulesi, bir erkek figürü, maskeler, Pasteur'ün büstü ve Meryem'e adanmış küçük bir anıt bulunmaktadır. Bu heykeller çimentodan şekillendirilmiş ve mozaikle kaplanmıştır (Resim 14). 


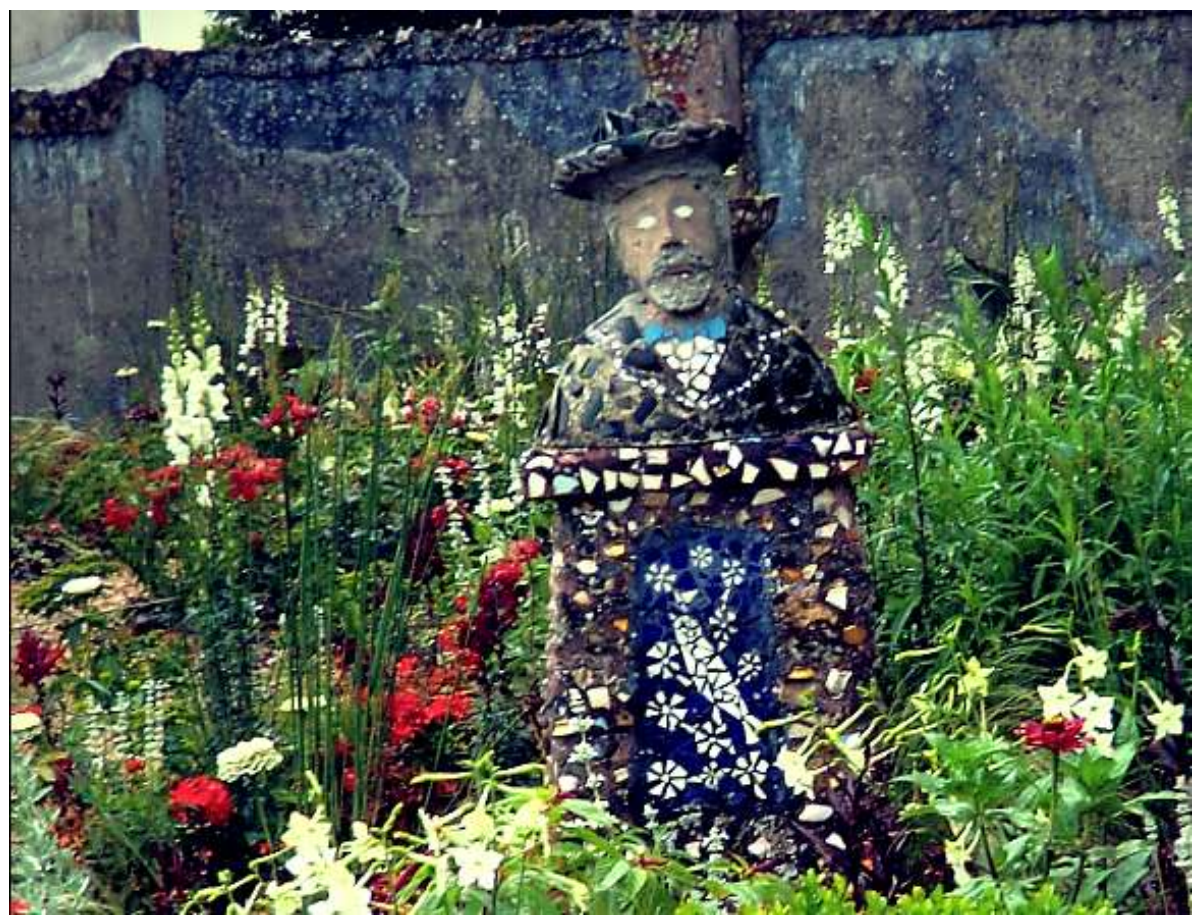

Resim 14 : Pasteur Büstü, Heykelli Bahçe

(http://ailonuage.canalblog.com/tag/Musées)

Ortasında bir havuz bulunan ve Kudüs duvarının bulunduğu bu bahçede, Fransız saraylarının bahçelerinde görülen süsleme stilinden etkilenilmiştir. Havuzun önünden basamaklarla çıkılan alanda bir taht vardır. Bu tahtın arkasında Kudüs kentinin betimlemesi yer almaktadır. Bu duvar siyah avlunun karşı çaprazındadır. $\mathrm{Bu}$ duvarda Siyah avluya göre oldukça açık renk hakimdir. Kudüs kenti betimlemesinin altında Colloseum, Pisa Kulesi gibi dünyadaki önemli yapılar beyaz seramik kırıklarıyla yapılmıştır. Kudüs kenti Isidore için gökseldir. Bu nedenle de siyah avlu yani yerselliği temsil eden duvarla karşılıklıdırlar (Resim 15). 


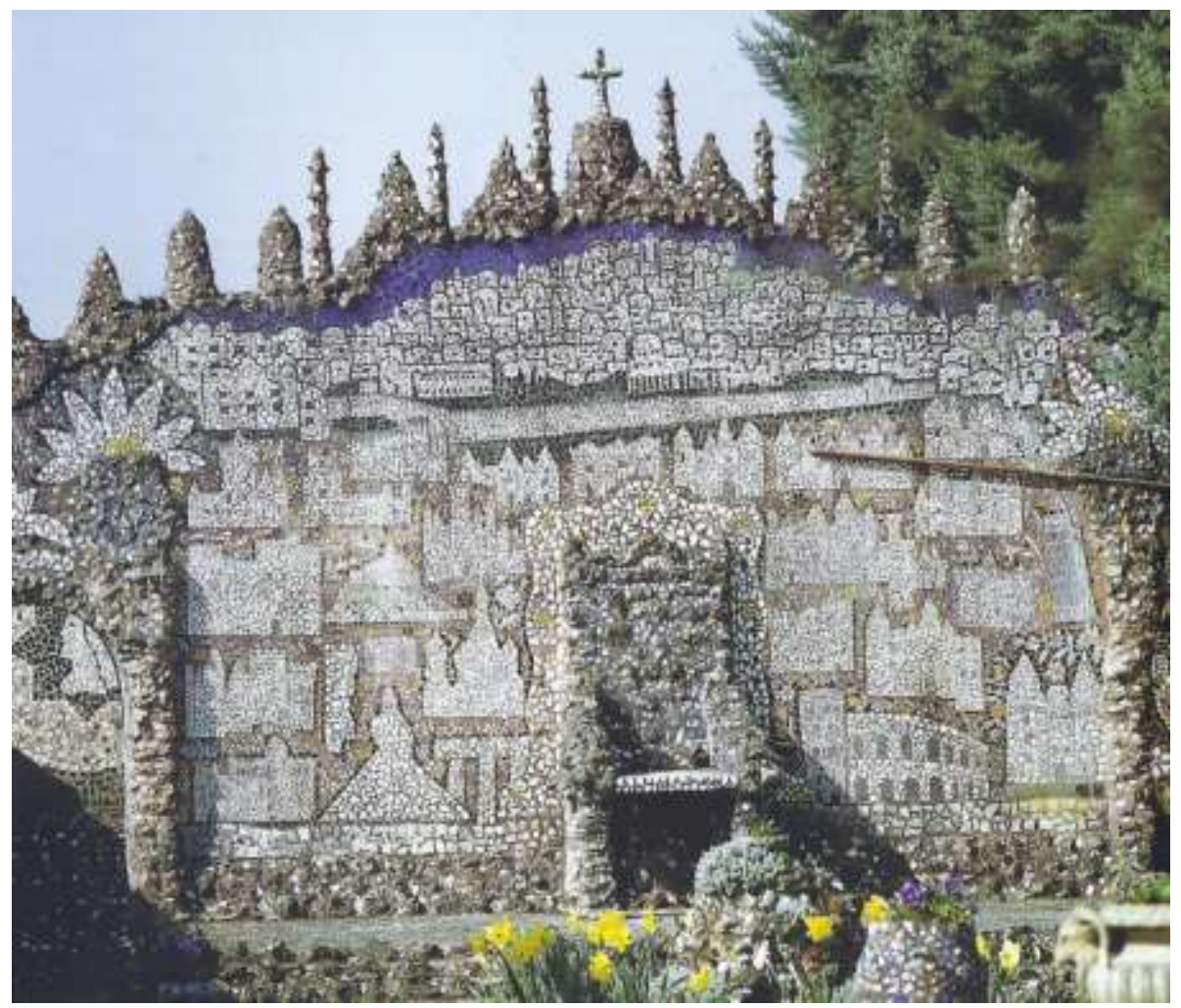

Resim 15 : Kudüs Duvarı

(Valles-Bled 2007: 29)

\section{Ruhun Mezarı}

Kudüs duvarının arkasında iki taraflı girişi olan küçük bir mekan yer almaktadır. Bu mekan Isidore tarafından Ruhun Mezarı olarak adlandırılmıştır. $\mathrm{Bu}$ mekanın ana rengi mavidir. Ortada yüksek bir kaidenin üzerinde dikilitaşa benzer bir anıt bulunmaktadır. $\mathrm{Bu}$ anıtın üzerinde dini konulu yazılar vardır. Isidore ruhun mezarının renginin mavi olması gerektiğini söylemiştir. Ona göre mavi gökselliğin rengidir (Valles-Bled 2007: 31). 


\section{Meyve Bahçesi}

Ruhun mezarının arkasında bulunan bu küçük bahçenin ortasında bir ağaç bulunmaktadır. Isidore hayattayken bu ağacın dallarına mozaikle kaplı vazolar asmıştır. Ancak günümüzde bu ağaçta birşey bulunmamaktadır. Burada Isidore'un çalışma mekanları olan küçük barakalar vardır.

\section{Sonuç}

Isidore kendi hayal dünyasını evine yansıtmış ve naif duygularla mozaik tasarımlar oluşturmuştur. Mezarlık temizleyicisi olarak çalışan Isidore, evinden bahsederken "o kadar çok şey atiyoruz ki.. Halbuki onlardan hayat dolu ve mutluluk verebilecek güzel şeyler yapabiliriz” (Kloss, 1979: 22) demiştir. Picassiette evi mozaik tekniği olarak incelendiğinde, Isidore’un seramik kırıklarını desensiz (düz renk), desenli olmak üzere farklı farklı kullandı̆̆ı izlenmiştir. Kimi yerlerde düz renkli seramik ve cam kırıkları bir araya getirilerek yeni motifler oluşturulmuştur. Kimi yerler de ise desenli seramik kırıkları bir araya getirilerek etkileri farklılaştırılmış ve bu desenlerin yeniden dizilimiyle farklı bir desen oluşturmuştur. Isidore özellikle insan figürlerini şekillendirirken küçük seramik ve cam kırıklarını bir araya getirmiş, mobilya, evin dış duvarı, tavan ve taban kaplamalarında genellikle büyük seramik ve cam kırıklarını kullanmıştır. İç mekan olarak şapel ve ruhun mezarında; dış mekan da ise siyah avlu duvarı ve Kudüs duvarında küçük seramik ve cam kırıklarını tercih edilmiştir. Isidore, yazlık evin dış cephesinde, siyah avluda, siyah tahtın arkasındaki duvarın üst süslemesinde ve Kudüs duvarının üst süslemesinde emzik, kulp, çanak ayakları, biblolar gibi kırık seramik objelerini de olduğu gibi kullanmıştır. Isidore, kimi yerlerde gri çimento kullanırken kimi mozaik kaplamalarda çimentoyu renklendirerek mavi olarak kullanmıştır. Evin ön cephesi mavi çimentoyla kaplanarak seramik kırıklarının renkleri bastırılmış ve mavi renk ön plana çıkmıştır. Bu cephe uzaktan izlendiğinde mavi olarak algılanmaktadır. Şapelde olduğu gibi bazı duvar kaplamalarında kırık seramik parçalarının arası oldukça açık bırakılmış ve mavi çimento derz dolgusundan çok, zemin olarak kullanılmıştır. Burada Isidore'un amacının gökselliği, ruhani dünyayı vurgulamak olduğu düşünülmektedir.

Seramik kırıklarının ön plana çıkması istenilen yerlerde ise derz dolgusu gri renktir. Isidore'a göre yerselliği, dünyevi hayatı temsil eden Siyah Avluda da gri çimento kullanılmasının amacı budur. Isidore çimentoyu sadece derz dolgusu olarak değil heykel yapmak için de kullanmıştır. Bu heykellerin bazıları tamamen mozaikle kaplanırken bazıları ise detayları ön plana çıkarmak için kısmen kaplanmıştır. 
Picassiette evi konuları bazında incelendiğinde ise, Isidore'un genel olarak, yaşadığı Chartres kentini, Chartres Katedralini, çiçek, hayvan ve insan figürlerini betimlediği görülmüştür. Chartres kentinde doğup büyüyen Isidore'un bu kentten etkilenmemesi mümkün değildir. Katedralin vitraylarının mozaik tarzına benzemesi nedeniyle dinsel yönü ağır basan Isidore'un mozaik fikri için buradan esinlendiği düşünülmektedir. Katedralin vitraylarındaki ağırlıklı rengin kobalt mavisi olması da Isidore'un mavi rengi, neden göksellik için düşündüğüne bir kanıt olarak gösterilebilir. Isidore ayrıca evin girişinde ve Siyah Avluda birçok kez gül pencere motifini kullanmıştır. Tabanda büyük olarak resmettiği bu motif güneşi andirmaktadır.

Mezarlık çalışanı olarak Isidore, naif duygularla, sanat eğitimi alamadan, özgün, yaşanmışlıklarını, hayal dünyasını çocuksu ifadelerle mozaik tekniğiyle resmederek benzeri olmayan çok farklı bir anlayışla kendi dünyasını ortaya koymuştur. Eşi ve çocukları için barınma amaçlı bir ev inşa eden Isidore, bununla yetinmeyip kendisine huzur verecek ve ruhani olarak huzur bulabileceği bir alan oluşturmuştur. Eşi için tasarladığı ve yoğun olarak kullandığ1 çiçek motifleri ise evde sürekli bir bahar havası varmış gibi izlenim vermektedir.

Seramik ve cam atıklarının kullanıldığı bir ev örneği olarak Picassiette evinin, atık malzemelerden de bir sanat eseri yaratılabileceğini göstermesi açısından önemli bir örnek olduğu düşünülmektedir. 


\section{KAYNAKÇA}

Kloss, Maarten. Le Paradis Terrestre de Picassiette. Paris: Encre, 1979.

Valles-bled, Maithe. Picassiette. Chartres: L'association Des Amis Du Musee Des Beauxarts de Chartres, 2007.

The joy of shards Mosaics Resource. "Mosaics and mosaic making information", 21 Haziran 2012. http://www.thejoyofshards.co.uk/index.shtml.

Goddard, Linda. "La Maison Picassiette." 21 Haziran 2012. Web. 13.07.2012. [http://www.rawvision.com/articles/la-maison-picassiette]

"Raymond Isidore dit Picassiette - Le Jardinier de la Porcelaine - Chartres Eure-et-Loir (28)", (16 Temmuz 2012) 3 Ağustos 2012. http://ailonuage.canalblog.com/tag/Musées

"Maison Picassiette à Chartres", (18 Haziran 2011) 18 Temmuz 2012. http://matinlumineux.blogspot.com/2011/06/maison-picassiette-chartres.html

Bush, Katie. "Field Trip: Maison Picassiette", (15 Temmuz 2012) 3 Ağustos 2012. http://www.thedailytelecraft.com/2012/07/field-trip-maison-picassiette.html
"Maison
Picassiette",
21
Haziran
2012.

http://www.raingod.com/angus/Gallery/Photos/Europe/France/Centre/images/PicassietteEave s01.jpg 